\title{
Psychosocial and Health Impact on the Healed People of Ebola in the City of Forecariah
}

\author{
Diallo AAS ${ }^{1}$, Keita $M^{4 *}$, Sylla AI ${ }^{1}$, Kourouma $F^{1}$, Sylla $D^{2}$, Doumbouya $A^{1}$, Bah $L Y^{3}$, Soumah \\ $\mathrm{AA}^{1}$, Diallo $\mathrm{AG}^{1}$ and Cisse $\mathrm{A}^{5}$ \\ ${ }^{1}$ Internal Medicine, Donka National Hospital, Conakry, Guinea \\ ${ }^{2}$ Medical Emergencies, Donka National Hospital, Conakry, Guinea \\ ${ }^{3}$ Department of Nephrology, Donka National Hospital, Conakry, Guinea \\ ${ }^{4}$ Psychiatry Department, Donka National Hospital, Conakry, Guinea \\ ${ }^{5}$ Department of Neurology CHU Ignace Deen, Rouen, France
}

"Corresponding Author: Dr. Keita MM, Psychiatry Department, Donka National Hospital, Conakry, Guinea; Tel: 224628779717 (or) 657408760; E-mail: saramady1957@ gmail.com (or) keitapsy@yahoo.fr

Received: 29 January 2018; Accepted: 20 February 2018; Published: 26 February 2018

\begin{abstract}
Introduction: Ebola virus disease is one of the most serious viral diseases known to man. It belongs to the filovirus family, with a case-fatality rate of $25 \%$ to $90 \%$. The aim of this study was to evaluate the psychosocial and health impact of Ebola virus disease on people who have been cured.

Method: This was a descriptive study of transversal type extending over a period of 3 months and focused on people cured of the Ebola virus disease of Forecariah prefecture.

Results: During the study period, we recorded 114 people cured of the Ebola virus disease in Forecariah prefecture, among whom we interviewed 101 people cured of Ebola virus disease (89\%). The socio-demographic characteristics of these healed people were: those of cures whose age ranged between 27-37 years with a frequency of $32.7 \%$ and extremes of 5-55 years. There was a female predominance with a sex ratio of 0.80 for women. Malaria was the most dominant antecedent. Social withdrawal $89.1 \%$, moral pain $72.2 \%$ and strong sense of guilt $45.5 \%$ were the most common psychiatric symptoms in cured people. The dominant somatic symptoms found were headache $36.6 \%$; while defamation $82.1 \%$ was the most dominant type of stigma.
\end{abstract}

Conclusion: Despite Significant Progress in Managing People Cured of Ebola Disease, National Study of Ebola Healers Could Better Identify EVD Impact on Healed Individuals.

Keywords: Impact; Psychosocial; Ebola; Healed; Forecariah 


\section{Introduction}

Ebola virus disease is one of the most serious viral diseases known to man. It belongs to the filovirus family, with a case-fatality rate of $25 \%$ to $90 \%$. [1] A person cured of Ebola Virus Disease (EVD) is defined as a person: with a confirmed positive result on reverse transcriptase polymerase chain reaction (RT-PCR) tests for the Ebola virus on a body fluid that subsequently reestablished or $\operatorname{IgM}$ and / or IgG positive on serological tests for EVD and not vaccinated against Ebola virus. [2] A study conducted by Post Ebola Guinea (POSTEBOGUI) in Conakry and Macenta on 301 cured patients discharged from CTE showed that 14\% of people said they had experienced discrimination at least once, most often through gossip or insults. Self-exclusion of social events was described by $15 \%$ of people, more frequently in the wake of the CTE exit. Some cured EVD patients have symptoms, or sequelae, after being discharged from the Ebola Treatment Center (ETC). According to the data of the review of the literature the most frequently encountered symptoms are mainly visual disorders with some complications, including uveitis, muscle, joint and abdominal pain, headache, asthenia, memory and hearing. Several psychic symptoms have been reported, ranging from anxiety, sleep disorders, to neuropsychiatric manifestations. Other signs such as erectile dysfunction, amenorrhea, decreased libido have also been reported [3]. Ebola virus disease is a life-threatening infectious disease, a major public health problem. This study aims to assess the psychosocial and health impact of Ebola virus disease on people who have been cured.

\section{Patients and Methods}

The prefecture of Forecariah served as a framework for our study. The study focused on people cured of Ebola virus disease identified on behalf of Forecariah prefecture organized in association called association of people cured of Ebola virus disease. This was a descriptive cross-sectional study lasting three (3) months from May 1st to July 31 st, 2016, inclusive involving people cured of Ebola.

The study population was represented by people cured of Ebola virus disease identified in Forecariah Prefecture and meeting our selection criteria during the study period. All those cured of Ebola Virus Disease (EVD) from Forecariah prefecture who have agreed to participate in our study and have an exit certificate regardless of age and gender have been included. All the healed people from the EVM of Forecariah prefecture who did not consent to the study and / or did not possess an exit certificate were not included.

\section{Results}

Forecariah Prefecture recorded a total of 114 people cured of Ebola and a total of 101 were included in our study. Socioprofessional characteristics The average age of people cured EVD was $29.02 \%$ and extremes of age from 7 years to 55 years. The most represented age group is that of 27-37 years, ie a proportion of 32.7\% followed by 17-27 years or $23.7 \%$. The female sex dominates our study population with a frequency of $55 \%$ against $45 \%$ for men and a sex ration of 0.8 for women The most represented profession was housewives (25.74\%) followed by students $(21.78 \%)$ and farmers (19.80\%). In this study we met $59.4 \%$ of married couples followed by single with $34.6 \%$. The sub-prefecture of Maferinyah was the locality that registered many people cured of the EVD with $28.7 \%$ compared to the urban community of Forecariah $14.9 \%$; Farmorah $12.8 \%$ and $10.9 \%$. 


\subsection{Clinical features}

Malaria accounted for $15.84 \%$ of history of cured EVD, followed by $0.99 \%$ of Arterial Hypertension. The average length of stay in the Ebola Treatment Center was $11.68 \pm 3.47$ with extremes of 5 to 21 days. Most of the cures had done 11-15 days before going out of the disease, $47.53 \%$ followed by 6-10 days or $29.70 \%$. Psychiatric symptoms are very common in the cured people of EVD and in our study, we encountered social withdrawal among our respondents in $89.1 \%$ of cases followed by moral pain or 72.25 ; a strong sense of guilt in $45.5 \%$ of cases, insomnia 13.8\%; the nightmare 11,85; multiple bereavements $10.8 \%$ (Table 1).

\begin{tabular}{|l|l|l|}
\hline Psychiatric Symptoms & Effective & pourcentage \\
\hline Social withdrawal & 90 & 89.1 \\
\hline Moral Pain & 73 & 72.2 \\
\hline Multiple mourning & 11 & 10.8 \\
\hline Suicidal Thinking & 2 & 1.9 \\
\hline Strong sense of guilt & 46 & 45.5 \\
\hline Nightmare & 12 & 11.8 \\
\hline Insomnia & 14 & 13.8 \\
\hline Amnesia & 4 & 3.9 \\
\hline Anxiety & 7 & 6.9 \\
\hline
\end{tabular}

Table 1: Distribution of people cured of Ebola virus disease by psychiatric symptoms.

Eye pain and vision loss were present in $1.9 \%$ of cases in our patients and red eyes were $0.9 \%$. The somatic symptoms were marked by headache with a proportion of $36.6 \%$ followed by muscle pain $24.7 \%$; joint pain and fatigue accounted for $22.7 \%$ (Table 2).

\begin{tabular}{|l|l|l|}
\hline Somatic Symptoms & Effective & Percentage \\
\hline Headache & 37 & 36.6 \\
\hline Fatigue & 23 & 22.7 \\
\hline Anorexia & 21 & 20.7 \\
\hline Joint pain & 23 & 22.7 \\
\hline Muscle pain & 25 & 24.7 \\
\hline Lumbar pain & 3 & 2.9 \\
\hline Decreased libido & 3 & 2.9 \\
\hline Abdominal pain & 11 & 10.8 \\
\hline
\end{tabular}

Table 2: Distribution of people cured of Ebola virus disease by somatic symptoms. 
Stigma was a recurring problem among all cured EVD patients, in our study defamation was the most common stigma aspect with $82.1 \%$ followed by Reintegration Difficulty in $78.2 \%$. case and rejection by friends $64.3 \%$ (Table $3)$.

\begin{tabular}{|l|l|l|}
\hline Stigma & Number & Percentage \\
\hline Refusal to share the same meal & 12 & 11.8 \\
\hline Loss of employment & 36 & 35.6 \\
\hline Difficulty getting a job & 7 & 6.9 \\
\hline Difficulty of social reintegration & 79 & 78.2 \\
\hline Refusal of physical contact & 23 & 22.7 \\
\hline Defamation & 83 & 82.1 \\
\hline Rejection by friends & 65 & 64.3 \\
\hline Reluctance to get in touch with others & 58 & 57.4 \\
\hline Refusal to display & 36 & 35.6 \\
\hline
\end{tabular}

Table 3: Distribution of people cured of Ebola virus disease by aspects of stigmatization.

\section{Discussion}

This study was carried out in Forecariah prefecture and interested people cured of the Ebola virus disease. It was a descriptive study of the transversal type for a period of 3 months from May 1st to July 31st, 2016. Its objective was to evaluate the psychosocial and health impact of the EVD on people healed from the prefecture. of Forecariah. During the course of the study we were confronted with the following difficulties: Difficulty of access of certain zones due to the bad state of the roads; Request for the interview premium by some cured people; the unavailability of some cured Ebola virus disease worried about the work field. In the face of the largest outbreak of Ebola virus disease ever seen, and with the improvements seen in the provision of care in the field, there is a high number of survivors of EVD, with a large number of people suffering from sequelae of the disease [4]. During the study period, we recorded 114 people cured of the Ebola virus disease in Forecariah prefecture, among whom we interviewed 101 people cured of Ebola virus disease (89\%).

This high rate of people cured of the Ebola virus disease interviewed in our study would be justified by the fact that the 101 people cured of the Ebola virus disease that constitutes our required sample had agreed to participate in our study and had an exit certificate. . The average age of our people cured of Ebola was 29.02 years with extremes of 7 and 55 years and the most represented age group was 27-36 years old, a frequency of $32.7 \%$. This could be explained by the fact that this age group is in the range of age-predictive factors that is between 5 and 45 years old, according to a cohort study carried out on patients hospitalized at CTE Conakry. Because ages not in this range were the most vulnerable and exposed to death. Our results are comparable to those found by Mattia JG et al. [5] found in their study of the systematic clinical evaluation of sequelae observed in 277 survivors of the 2014-2015 epidemic in Sierra Leone an average age of 29 years. The age group 27 to 37 years was the most represented with a frequency of $32.7 \%$. The people cured of the Ebola virus disease of the prefecture of Forecariah were predominantly female; 56 women or $55 \%$ against 45 men or $45 \%$ with a sex ratio of 0.80 for women. 
This high rate of female sex is explained by the fact that it was this layer that played the role of family caregivers, caring for the sick, cleaning the waste in the home and being exposed to all the factors. of risks. Our results are inferior to those found by Mattia JG et al. [5] who found in their study of the systematic clinical evaluation of the sequelae observed in 277 survivors of the 2014-2015 epidemic, in Sierra Leone 163 were women or 59\% against 114 men or $41 \%$. Our study revealed a large number of housewives among the cured, ie $25.7 \%$ followed by students, that is $21.7 \%$ and farmers $19.8 \%$. This result corroborates the predominance of the female layer found in our study and could still be explained by their role as family caregiver because she spends most of their time looking after their family. Thus, during our study, we noted that the majority of people cured of the Ebola virus disease of the prefecture of Forecariah were married or $59.4 \%$, followed by singles $34.6 \%$, widowers $4 \%$ and divorced $2 \%$. This is explained by the predominance of adults in our study, this group of individuals was exposed to risk factors or modalities of contamination in the family environment, namely: family care, funeral toilets and family obligations. Our study shows that most of our people cured of Ebola virus disease live in the Maferinya sub-prefecture (28.7\%), followed by the urban commune (14.9\%). This could be explained by its proximity to the prefecture of Coyah from where the disease left for the prefecture of Forecariah. The antecedents of the cured people in our study were dominated by malaria at $15.84 \%$. Guinea being a malarial endemic area and located in zone 3 according to the geographical distribution of malaria endemic areas could be the explanation of these data.

In our study, the length of stay in the most represented Ebola treatment centers was 11-15 days, with 48 people cured of the Ebola virus disease (47.53\%). The average length of stay cured of Ebola virus disease in our study was $11.68 \pm 3.47$ days with extremes of 5 and 21 days. It is during this period that the immunity begins to rebuild and the 14 th is the beginning of the convalescence period in the EVD. The 6th is the appearance of IgM antibodies, which lasts 3 to 6 months after the clinical cure, while the $\mathrm{IgG}$ antibodies begin to appear from the 10th day and lasts 3 to 5 years see the whole life. The fall in viremia that begins from the 10th day shows the disappearance of clinical signs especially fever, this absence of clinical signs motivated the realization of two RT-PCR to confirm the cure. Most of the patients were cured within this range of 11 to 15 days of hospitalization as shown by our result. Social withdrawal was the main psychiatric symptom most reported by the cured $89.1 \%$ followed by moral pain is $72.2 \%$ and the strong sense of guilt is $45.5 \%$. Several factors could explain this result: the loss or the change of social and / or family status, the material losses, the loss of the sources of income, the stigmatization, the social isolation, the feeling of abandonment felt after the Out of the Ebola treatment center, the length of hospital stay also contributed to seeing their loved ones suffer or die in front of their eyes without being able to help them and the longer the length of time elapsed the more patients found themselves in the hospital. a traumatic situation.

The headaches were the most reported somatic symptoms by our people cured of the Ebola virus disease 36.6\%. These headaches are called tension headaches caused by the presence of post- traumatic stress after they are released into the ETC. The High Council for Public Health [6]: in a follow-up study of cohorts from Conakry and Macenta covering 375 survivors as of December 15, 2015, found 32\%, headache. Ocular symptoms were dominated by eye pain and vision loss of $1.9 \%$ each. The ocular symptoms appeared in the majority of people cured of the EVD, because the presence of the virus in the eye remains to know if it is the active or inactive form and determined the virological kinetics at the level of the 'eye. Occurrence of ocular symptoms emphasizes the importance of early monitoring for eye sequencing, ideally in the first or second week after leaving the Ebola treatment center. This rate 
of ocular symptoms is lower than reported by Jay B.V et al. [7] who in their study revealed that $60 \%$ of the cured patients reported an ocular symptom. Defamation, difficulty reintegrating into society, and rejection by friends were the types of stigma that healed people experienced, respectively: $82.1 \%, 78.2 \%$, and $64.3 \%$. This result could be explained by the lack of community ownership of the support provided to people cured of the Ebola virus disease, the community's ignorance of the disease, and the lack of social support by the EVD agencies.

\section{Conclusion}

In our study, 101 people cured of the Ebola disease met our selection criteria whose socio-demographic characteristics were relatively young with an average age of 29 years and extremes of 7 and 55 years, there is a female predominance either 56women against 45 men. The symptoms reported by our cured people of Ebola disease are both psychiatric, somatic and ocular. The majority of the healed people were victims of defamation, difficulty of social reintegration and rejection by friends. A national study of people cured of Ebola could help identify their problems.

\section{References}

1. Ministry of Social Affairs, Health and Women's Rights. Update on infectious risk 2 (2014): 1.

2. UNICEF. Ebola: Goal zero, for communities, for children, for the future. 19 (2014): 6 .

3. Sama R. Plan-Strategic-Survivors-Guinea. 81 (2016): 6.

4. CDC. Interim Guidelines for the Management of Ebola Survivors in Health Care Facilities in the United States.

5. Mattia JG, Vandy MJ, Chang JC, et al. Early clinical sequelae of Ebola virus disease in Sierra Leone; Cross-sectional study. Infectious Lancet Dis 16 (2016): 331-338.

6. High public health council. Advice on how to deal with the risk of viral resurgence in patients considered cured of EVD and the care of their contacts. 11 (2016).

7. Jay BV, Jessica GS, Crozier I, et al. Persistence of Ebola Virus in Ocular Fluid during Convalescence. N Engl J Med 372 (2015): 2423-2427.

Citation: Diallo AAS, Keita MM, Sylla AI, Kourouma F, Sylla D, Doumbouya A, Bah LY, Soumah AA, Diallo AG and Cisse A. Psychosocial and Health Impact on the Healed People of Ebola in the City of Forecariah. Journal of Psychiatry and Psychiatric Disorders 2 (2018): 23-28.

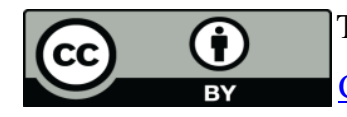

This article is an open access article distributed under the terms and conditions of the Creative Commons Attribution (CC-BY) license 4.0 